\title{
10 ANOS DO IFA-FIVU: UMA HISTÓRIA TECIDA A MUITAS MÃOS
}

\author{
Apresentação do Dossiê Especial Formação para a vida acadêmica: \\ objetos de aprendizagem, políticas linguísticas e formação de professores \\ de línguas em contexto extensionista
}

\author{
Deise Cristina Lima PICANÇO \\ Universidade Federal do Paraná \\ deisepicanco@gmail.com \\ https://orcid.org/0000-0002-2234-2090 \\ Angela Maria Hoffmann WALESKO \\ Universidade Federal do Paraná \\ angelawalesko@gmail.com \\ https://orcid.org/0000-0001-7234-3350 \\ Julio MARQUES \\ Faculdade Educacional da Lapa \\ juliocezar.marques@gmail.com \\ https://orcid.org/0000-0001-6063-8020
}

A internacionalização das instituições públicas de ensino superior tem sido um importante desafio diante de um processo de globalização do consumo e das comunicações, que criou diferentes formas de socialização tornando urgente compreendermos seus efeitos sobre vários aspectos da vida social, em especial dos anos de vida acadêmica dos nossos estudantes. Portanto é preciso refletir sobre os modos como os discursos se organizam, muitas vezes reiterando ideologias hegemônicas, regulando performances identitárias e naturalizando relações de poder.

No contexto acadêmico, o acesso a outras manifestações linguísticas por meio do aprendizado de outros idiomas pode ser uma oportunidade para que surjam novas compreensões sobre a ciência e a realidade científica; pode ser uma nova possibilidade de manifestação ou de expressão da própria subjetividade; pode ser também uma oportunidade de enfrentamento dos desafios que as culturas e as ideologias propõem às estruturas sociais consolidadas. $\mathrm{O}$ valor social de uma língua deriva das relações de poder que se estabelecem na composição dos espaços em que circula, servindo em muitos momentos como lugares de minorização, exclusão e desigualdade (DEL

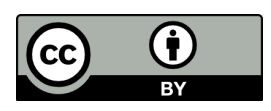


VALLE, 2017). Por isso, é preciso destacar que uma educação comprometida com a superação das desigualdades exige a inclusão de todos os segmentos sociais no mundo globalizado (SANTOS, 2000) por meio do acesso a outras língua(gen)s e seus processos de produção de conhecimento.

Nesse sentido, no ano de 2009, o Projeto Formação em Línguas para Fins Acadêmicos, que ficou conhecido como Idiomas para Fins Acadêmicos (IFA) e depois Formação em Idiomas para Vida Universitária (FIVU), observando a situação dos acadêmicos da UFPR, iniciou suas atividades, visando, por um lado, contribuir de forma decisiva na formação de professores dos cursos de Letras, e, por outro, possibilitar aos acadêmicos com vulnerabilidade econômica o acesso ao aprendizado de línguas estrangeiras com objetivos acadêmicos.

Naquele ano, os professores ${ }^{1}$ de Metodologia e Prática de Docência em línguas estrangeiras do Departamento de Teoria e Prática de Ensino (DTPEN) foram convidados pela Pró-Reitoria de Assuntos Estudantis (PRAE) para conversar sobre uma parceria num projeto direcionado aos estudantes cadastrados no Programa de Bolsa Permanência (PROBEM) do MEC (PBP/MEC). Após uma longa conversa, ficou definido, em conjunto, que, entre os objetivos do projeto, estaria a possibilidade de os alunos de Letras atuarem como professores em formação, em cursos de línguas planejados a partir de programas totalmente vinculados à vida acadêmica, em seu sentido amplo, com temáticas sociocomunicativas, numa perspectiva bakhtiniana e sociodiscursiva. Ainda que usássemos o termo fins acadêmicos, os cursos oferecidos não eram cursos instrumentais para aprendizagem unicamente de gêneros discursivos do mundo acadêmico, como resumos, resenhas e artigos, mas tinham o propósito de democratizar o acesso às línguas e à vida universitária.

De 2009 a 2014, enquanto o projeto esteve vinculado a essa parceria, as assistentes sociais da PRAE foram imprescindíveis, pois validavam as inscrições e nos ajudavam no contato com os alunos. Como o projeto foi ficando cada vez mais conhecido, para facilitar, os alunos passaram a chamá-lo de Idiomas para Fins Acadêmicos (IFA) e esse nome fantasia passou a fazer parte da identidade do projeto.

Desde o início, além dos bolsistas, os alunos de Prática de Docência passaram a ministrar aulas como parte de seu estágio de formação obrigatório no IFA. Os cursos e demais atividades, entendidas como extensão universitária, têm sido certificados para os bolsistas e praticantes e também para os alunos que fazem os cursos.

\footnotetext{
${ }^{1} \mathrm{Na}$ época eram os professores Henrique Evaldo Janzen e Deise Picanço. 
Em 2015, com a mudança nas políticas de permanência, o IFA passou a ser um Projeto de Extensão, não mais vinculado à PRAE e sim à Pró-Reitoria de Extensão e Cultura, contando com três professores formadores. A equipe se ampliou, nos anos de 2016 e 2017, e passou a atuar de acordo com as suas áreas de formação: Deise Picanço e Fernanda da Silva Veloso, na área de neolatinas; Flavio Ricardo Medina de Oliveira, na área de japonês; Ângela Maria Hoffmann Walesko e Catarina Portinho Nauiack, na área de anglo-germânicas (após a aposentadoria do professor Henrique Janzen).

Além das pró-reitorias, da direção do Setor de Educação e do DTPEN, o projeto também contou com o apoio do Núcleo de Assessoria Pedagógica (NAP) nos anos de 2016 e 2017. Em 2018, passamos a ocupar a copa do Setor de Educação, que serviu como espaço de interação, realocada, em 2019, para o prédio do Campus Rebouças, onde passamos a contar também com um laboratório maior e mais bem equipado, para aulas e demais atividades do projeto.

Embora tenhamos optado por não transformar o projeto num programa de extensão, após seus 10 anos de existência, a enorme procura por seus cursos (que chegava a representar três vezes o número de vagas ofertadas) e os resultados no âmbito de formação docente inicial e de elaboração de materiais didáticos (compartilhados em diversos eventos acadêmicos internos e externos e em publicações de artigos e capítulos de livro) deram fôlego para uma nova etapa do projeto, que passou a se chamar Formação em Idiomas para Vida Universitária (FIVU) — considerando o que já fazíamos, que era abordar a vida acadêmica nos mais variados âmbitos.

A experiência, vivenciada pelos diversos atores sociais que passaram pelo projeto, pode ser narrada a partir de diversas perspectivas, conectadas por uma visão crítica e consciente da linguagem, do que ela representa e de como ela se materializa no contexto social.

Esses dez anos de práticas e de formação docente nos impelem a um momento de reflexão sobre os avanços, as fragilidades, os desafios e as conquistas alcançadas na docência, na academia, nas ciências, e também sobre o momento sócio-históricopolítico que vivemos. Escrevemos, portanto, este dossiê, num momento crítico, no contexto da Pandemia causada pelo vírus Sars Cov 2, que atingiu um número trágico de mortes pela Covid19 e após o golpe de 2016, que colocou o país numa trajetória conservadora, de retirada de direitos dos trabalhadores e de intensificação dos ataques aos serviços públicos, à educação, à ciência e à democracia. Fazer um exercício de reflexão, valorizando os espaços de extensão universitária, do fazer coletivo e da democracia como princípio fundamental das relações humanas nesse momento é como 
(re)inscrever na história as nossas vivências. É (re)viver, como memória, aquilo que experienciamos como cotidiano. Esse é o propósito deste dossiê: abrir espaço para que aqueles que vivenciaram, como parte de seu cotidiano formativo, as ações do projeto, possam realizar uma reflexão sobre os aspectos linguísticos, culturais, identitários e institucionais que os afetaram nesse período. Esperamos que essas reflexões tragam para os leitores a possibilidade de conhecer esse trabalho extensionista e formativo em suas mais variadas facetas, ajudando assim a compor um amplo espectro de possibilidades de atuação nas áreas de educação, linguística aplicada e formação de professores.

A proposta deste dossiê, dividido em três partes, é concentrar trabalhos dedicados à investigação das ações pedagógicas, das produções didáticas e dos processos de formação e suas implicações: para o desenvolvimento de novas formas de aprendizagem de línguas (KALANTZIS; COPE, 2012); para os multiletramentos (COPE; KALANTZIS, 2000) e o letramento crítico (FREEBODY; MUSPRATT; LUKE); para compreender as ideologias e as práticas discursivas presentes na educação linguística (ARNOUX; BEIN, 2015; VOLOCHINOV, 1929), tais como as ideologias linguísticas (ARNOUX; DEL VALLE, 2018; KROSKRITY, 2014) e econômicas (WRIGHT, 2019); para entender de que modo se constroem discursivamente as performances identitárias (HOOKS, 2014) e suas relações de poder (GUATARRI; ROLNIK, 1999; FOUCAULT, 1979), podendo mesmo propor novas articulações com a educação crítica (FREIRE, 1968).

Assim, na Parte I, "Produções didáticas", as leitoras e os leitores encontrarão o primeiro artigo, de Lopes e Garcia, intitulado "Movimento cartonero visto sob uma concepção de língua sociointeracionista: trajetos latino-americanos e autoria no ensino de espanhol", no qual as autoras analisam partes de uma unidade temática voltada ao processo de criação de livros cartoneros, uma forma cooperativista/popular de publicar livros de modo acessível em meio a um cenário de crise econômica (RODRIGUES, 2011); no segundo artigo, "Biography and storytelling: a identidade e a subjetividade na aula de inglês no IFA/FIVU", Silva e Dalfovo apresentam de forma bastante articulada o processo de criação de unidades temáticas, analisando de que maneira é implicada a subjetividade nos materiais elaborados e como se articula com o debate sobre a importância da alteridade no processo de construção da identidade (HALL, 2007; AUTHIER-REVUZ, 1990; JOUVE, 2013; MORRISON, 2017) e da interculturalidade (GIMENEZ, 2001; BHABHA, 1998); e, finalizando essa parte, Fernandes Vailatti nos traz seu artigo intitulado "Curso de francês do projeto formação em línguas para fins acadêmicos: considerações sobre os materiais didáticos e suas contribuições metodológicas", elaborado a partir de uma perspectiva qualitativa, interpretativa e 
documental, versando sobre as principais contribuições metodológicas dos materiais do IFA/FIVU, sob a perspectiva da teoria bakhtiniana de linguagem (BAKHTIN, 1992, 1998; VOLOCHINOV, 2017) e de conceitos da Didática de Ensino de Línguas (PUREN, 1988; CUQ; GRUCA, 2005; TILIO, 2013; ROJO, 2013).

$\mathrm{Na}$ Parte II, "Ensino remoto em caráter emergencial", as reflexões voltadas ao contexto de sala de aula, presencial ou virtual, partem de discussões sobre programas, práticas docentes e diálogos teóricos, que se materializam em materiais didáticos e em práticas pedagógicas. O primeiro artigo, escrito por Herrera e Veloso, sob o título de "A intercompreensão no ensino do espanhol: vivências em um curso online do FIVU", trata das atividades elaboradas para um curso espanhol básico, voltado a um público de pósgraduandos. Em seu texto, as autoras apresentam e analisam algumas práticas levadas a cabo a partir dos pressupostos da intercompreensão entre línguas românicas (ESCUDÉ; OLMO, 2019); escrito por Pizza e Eugênio, o segundo artigo dessa parte encontra-se no contexto das ações extensionistas em modalidades virtuais. Sob o título de "Espanhol como língua estrangeira em tempos de pandemia: atividades síncronas que apenas o ensino remoto proporciona", as autoras nos apresentam uma interessante discussão sobre a adaptação de professores e alunos ao ensino remoto emergencial, destacando atividades planejadas para esse momento específico e apresentando os resultados obtidos a partir de atividades práticas; no terceiro artigo, de Rabanéa, Arruda e Veloso, intitulado "Medianeras a brasileña: como construir e trabalhar relações interpessoais em cursos online de espanhol?", somos brindados por uma ressignificação das reflexões apresentadas no filme Medianeras (2011), sobre as relações mediadas pela tecnologia, tema extremamente relevante para o contexto atual. São abordadas as dinâmicas desenvolvidas para adaptar as interações ao contexto pandêmico, sobretudo as relações professor-aluno, pensando no contexto formativo do projeto em questão, retomando importantes postulados sobre as maneiras de utilizar as mídias em prol dos processos de ensino-aprendizagem (MORAN, 2000).

E, para finalizar, na Parte III, trataremos dos "Processos de formação, ações pedagógicas e suas implicações", num conjunto de textos dedicado às reflexões sobre a práxis pedagógica e seus desdobramentos teórico-reflexivos em diversos contextos. O primeiro artigo, escrito por Walesko e Portinho-Nauiack, intitulado "Que tal uma pausa para um 'Café Cultural'? Interculturalidade e (trans) formações de identidades de professores de línguas", trata de uma das destacadas ações pedagógicas desenvolvidas por professores e professoras, formadores e em formação, do IFA/FIVU ao longo dos últimos anos. A partir de uma perspectiva qualitativa e etnográfica, as autoras ressignificam 
paradigmas sobre os processos de construção identitária de professores que impactam o ensino-aprendizagem de inglês como uma língua franca (ILF), a partir do diálogo intercultural com falantes nativos de línguascultura diversas. O artigo fundamentase principalmente em textos sobre interculturalidade (KUMARAVADIVELU, 2012; PICANÇO, 2012), sobre translinguismo (GARCIA; WEI, 2014, CANAGARAJAH, 2013, 2017) e sobre crenças e identidades docentes (BARCELOS, 2004, 2006, 2008; BERNAT, 2008) e sua relação com o "mito do falante nativo" (WALESKO, 2019). No segundo artigo, de Oliveira e Miranda, intitulado "A influência da autonomia nos processos de ensino e aprendizagem de língua estrangeira", acessamos uma relevante reflexão sobre a cultura da autonomia (HOLEC, 1981; 2008) e da sua importância para o desenvolvimento de alunos, mas também de professores em formação, destacandose a relação desses processos com a abordagem teórico-metodológica da pesquisaação (CARRS; KEMMIS,1986); o terceiro artigo dessa parte, de Picanço e Stemberg, intitulado "Análise de dois programas (UFPR e USP) de formação de estudantes de francês com objetivos universitários (FOU): concepções, conteúdos e modalidades", apresenta um estudo comparativo entre dois programas de ensino de francês com objetivos universitários, destacando-se os processos de seu desenvolvimento em duas universidades públicas, e da relevância e singularidade das suas ações para a construção de paradigmas no âmbito do ensino de línguas estrangeiras para fins específicos (CHAVES, 2006; FERREIRA; ROSA, 2008; CELANI, 1997).

O presente dossiê foi organizado como uma forma de disseminar as ideias e ações desenvolvidas por professoras e professores ao longo dos 10 anos do IFA/FIVU, não apenas como um registro, mas como um incentivo à criatividade, à construção de saberes e à resistência e ressignificação em tempos de crise.

Desejamos a todas e todos uma excelente leitura e abrimos o convite ao diálogo, sempre.

\section{REFERÊNCIAS}

DEL VALLE, Jose. Glotopolítica y teoria del lenguaje. In: AGLO 2017 \# 1. Anuario de Glotopolítica. Buenos Aires: Editorial Cabiria, 2017.

SANTOS, M. Por uma outra globalização: do pensamento único à consciência universal. Rio de Janeiro: Record, 2000. 